\title{
Comparative Psychopathology of Women With Bulimia Nervosa and Obsessive-Compulsive Disorder
}

\author{
Cynthia M. Bulik, Deborah C. Beidel, Erich Duchmann, Theodore E. Weltzin, and Walter H. Kaye
}

Twenty women with bulimia nervosa (BN) and 20 women with obsessive-compulsive disorder $(O C D)$ were compared on responses to the Minnesota Multiphasic Personality Inventory (MMPI), Symptom Checklist-90-Revised (SCL-90-R), and the Beck Depression Inventory (BDI). Multivariate analyses showed no significant differences between bulimic and $O C D$ women on the MMPI, although a greater number of bulimic women showed significant elevations on several of the clinical scales. Analyses of SCL-90-R profiles

A LTHOUGH its precise etiology is unknown, bulimia nervosa (BN) has been viewed as a disorder of weight and appetite dysregulation influenced by factors such as sociocultural pressures to be thin, need for perceived control, affective disturbances, and neurochemical abnormalities. ${ }^{1-3}$ In addition, obsessive and compulsive features have been noted in women with $\mathrm{BN}$ and its symptoms have been likened to an obsessive-compulsive syndrome. ${ }^{4-6}$ In advanced stages of the disorder, the bulimic woman can occupy several hours per day thinking about food and engaging in binge-purge activities. Rosen and Leitenberg ${ }^{5}$ highlight a parallel between this cycle and behaviors commonly seen in individuals with obsessive-compulsive disorder (OCD). They noted that the purging serves to "undo" the effects of binging by preventing weight gain (or the anxiety caused by overeating) in much the same way that compulsive handwashing, for example, undoes the effects of contamination (i.e., it is anxiety-reducing). Purging is therefore negatively reinforced by reducing the bulimic's fear of weight gain. However, important differences do exist. Unlike the individual with $O C D$ who avoids situations in which contamination could occur, the bulimic individual appears to self-induce the anxiety-provoking

From the Department of Psycholog, University of Canterbury, Christchurch, New Zealand; the Western Psychiatric Institute and Clinic, University of Pittsburgh School of Medicine, Pittsburgh, PA; and the Department of Psychology, Louisiana State University, Baton Rouge, LA.

Address reprint requests to Cynthia M. Bulik, Ph.D., Department of Psychology, Private Bag, University of Canterbury, Christchurch 1, New Zealand.

Copyright 11992 by W.B. Saunders Company

$0010-440 X / 92 / 3303-0012 \$ 03.00 / 0$ indicated higher scores on somatization, interpersonal sensitivity, and psychoticism in the BN sample. Bulimic women did not differ significantly from $O C D$ women on either obsessive-compulsive measures or other measures of anxiety. Similarities and differences in symptom profiles between these two groups are discussed, as well as their implications for alternative treatment approaches for BN.

Copyright $\odot 1992$ by W.B. Saunders Company

state of fullness, which she then counteracts by purging.

Despite their symptomatological similarities, few studies have directly compared bulimic and OCD patients; however, several lines of evidence suggest this may be a worthwhile area of inquiry and one which may eventually lead to enhanced treatment approaches for $\mathrm{BN}$.

It has been well established that patients with anorexia and BN have increased risk for major affective disorder for themselves and in their family members. ${ }^{7-9}$ Much less attention has been directed toward delineating the comorbidity and family profiles of anxiety disorders in this group. In a review of 11 studies of comorbid features of anorexia patients (both bulimic and restrictor anorectics were included in many of the studies), Rothenberg ${ }^{10}$ concluded that obsessive-compulsive features were the second most frequently reported comorbid features of eating disorders. Depression, as predicted, ranked first. The results of this summary report were difficult to interpret, as the data represented subjective reappraisals of studies that employed a vast range of diagnostic and evaluation procedures.

Individual studies of the lifetime prevalence of OCD in women with eating disorders have reported $15 \%$ to $69 \%$ in women with anorexia nervosa only, $7 \%$ to $33 \%$ in women with $\mathrm{BN}$ only, and $15 \%$ to $44 \%$ in women with both disorders. ${ }^{8,11,12}$

Studies that focused on familial psychopathology have yielded little information regarding the prevalence of anxiety disorders in family members of bulimic women. Several investigations failed to report data for the anxiety disorders. ${ }^{13-15}$ Those that did generally found low morbid risks ${ }^{11}$ or low prevalence ${ }^{8}$ of anxiety 
disorders in relatives of patients with eating disorders. Methodological complications included failure to assess the relatives directly and utilization of instruments that may have been insufficient to provide reliable anxiety disorders diagnoses.

A second relevant area of inquiry includes psychometric analyses. Studies of bulimic women generally have revealed a depressed, anxious, and obsessional symptom profile. Bulimic women often produce Minnesota Multiphasic Personality Inventory (MMPI) profiles with elevated depression (D); psychopathic deviate (Pd), psychasthenia $(\mathrm{Pt})$, and schizophrenia $(\mathrm{Sc})$ scales. ${ }^{16-18}$ Similarly, OCD patients commonly exhibit elevations on the $\mathrm{D}, \mathrm{Pt}$, and Sc scales. ${ }^{19,20}$

The only study to our knowledge that has directly compared $\mathrm{BN}$ and OCD samples showed that the eating disorder patients (a combined anorexia and $\mathrm{BN}$ group) scored more similarly to obsessionals than to individuals with other anxiety disorders. ${ }^{6}$ Unfortunately, the eating disorders data were collected an average of 12 years after the anxiety disorders data, introducing multiple potential sources of error.

This study was designed to assess similarities and differences in female patients with BN and OCD on measures of general psychopathology, depression, anxiety, and obsessionality.

\section{METHOD}

\section{Subjects}

All subjects were initially screened using the Initial Evaluation Form (IEF), a semistructured interview routinely used at Western Psychiatric Institute and Clinic (WPIC) ${ }^{21}$ Following this interview, patients were referred to either specialized eating or anxiety disorders clinics for further evaluation and treatment.

The BN group consisted of 20 women who met DSM-III$R^{22}$ criteria for $B N$. The 20 subjects were randomly selected from a patient list of all inpatient admissions in 1989. Subjects younger than 17 or older than 50 were excluded from the study. The IEF diagnoses were confirmed by consensus of the two treating psychiatrists (W.H.K. and T.E.W.) and using self-report ratings from the Diagnostic Schedule for Eating Disorders-Revised (DSED-R). ${ }^{23}$ No bulimic patient had been given a concurrent diagnosis of $O C D$ at the time of admission. Subjects with the diagnosis of eating disorder not otherwise specified were excluded. Of the 20 bulimic women, five were at low body weight (defined as $<85 \%$ of ideal body weight [IBW]), four reported a history of low body weight, and 11 had never been significantly underweight.

The OCD group included 20 women who met DSM-III-
$\mathrm{R}^{22}$ criteria for $\mathrm{OCD}$. These women were consecutive cases seen by the Anxiety Disorders Clinic at WPIC. Initial IEF diagnoses were confirmed using the Anxiety Disorders Interview Schedule-Revised (ADIS-R) ${ }^{24}$ and a variety of self-report inventories. Six OCD patients were hospitalized and 14 were treated with intensive outpatient intervention. Subjects above the age of 50 were excluded from the study. No OCD patient had been given a concurrent diagnosis of any eating disorder.

\section{Procedure}

Both BN and OCD subjects completed the psychological battery before initiation of their respective treatment programs. All subjects completed the MMPI, ${ }^{25}$ the Symptom Checklist-90-R (SCL-90-R), ${ }^{2 .}$ and the Beck Depression Inventory (BDI). ${ }^{27}$ The battery was chosen to measure general psychopathology, depression, anxiety, and obsessionality.

\section{RESULTS}

\section{Data Analysis}

Age and BDI scores were compared using univariate $t$ tests. Two multivariate analyses of covariance (MANCOVAs) were performed comparing differences between $\mathrm{BN}$ and $\mathrm{OCD}$ women on the MMPI and SCL-90-R scales. Univariate ANCOVAs were then performed on the significant MANCOVA. To determine whether the scale scores could discriminate between the BN and OCD groups, a stepwise discriminant analysis was performed followed by a classification analysis. All analyses were performed using the Statistical Analysis System. ${ }^{28}$

Age

The bulimic women were significantly younger than the OCD women $(23.4 \pm 5.0 v 30.6 \pm 7.9$ years; $t=3.5, d f=38, P<.0001)$.

\section{$B D I$}

The BN group scored significantly higher on the BDI than the OCD group (BN, $30.2 \pm 10.4$; $\mathrm{OCD}, 21.1 \pm 12.6 ; t=2.5$, $d f=38, P=.02$ ). The mean BDI score indicates severe depression for the BN group and moderate-severe depression for the OCD group.

\section{MMPI}

MANCOVA was conducted comparing the $B N$ and OCD samples on the MMPI. All $t$ scores for scales 1 to 10 were entered into the analysis. Age was entered as a covariate. The 
overall MANCOVA was not significant (Wilk's $\Lambda=0.6, \mathrm{~F}=2.0, d f=[10,28], P=.07$ ). Further univariate analyses were therefore not performed.

To explore further the nature of similarities and differences in response patterns between $\mathrm{BN}$ and OCD women, we plotted the mean MMPI profiles for the two groups (Fig 1). Interestingly, the pattern of response was similar between groups, but the $\mathrm{BN}$ mean profile indicated greater overall psychopathology. The mean MMPI profile for the BN group was a 2-4-7-8 profile, and the mean OCD profile was a 2-7 high point pair.

As profiles based on group means can occasionally be misleading, we examined profile patterns for individual subjects and the number of subjects in each group who had $t$ scores greater than 70 on each of the clinical scales. For the BN group, one subject had a 2-4-7-8 profile, and five had a 2-7-8 profile. Ninety-five percent of the bulimic women had an elevated scale $2,75 \%$ an elevated scale $4,85 \%$ an elevated scale 7 , and $85 \%$ an elevated scale 8 .

For the OCD group, two subjects displayed the 2-7 high point pair, and seven had a 2-7-8 profile. Seventy-five percent of the OCD women had an elevated scale $2,80 \%$ an elevated scale 7 , and $55 \%$ an elevated scale 8 .

Chi-square analyses indicated that significantly more bulimic women than OCD women had elevations on MMPI scales Hs (hypochondriasis) and Pd (Table 1).

\section{$S C L-90-R$}

A second MANCOVA was then performed comparing SCL-90-R $t$ scores between $\mathrm{BN}$ and OCD samples. Age was entered as the covariate. The overall MANCOVA was significant

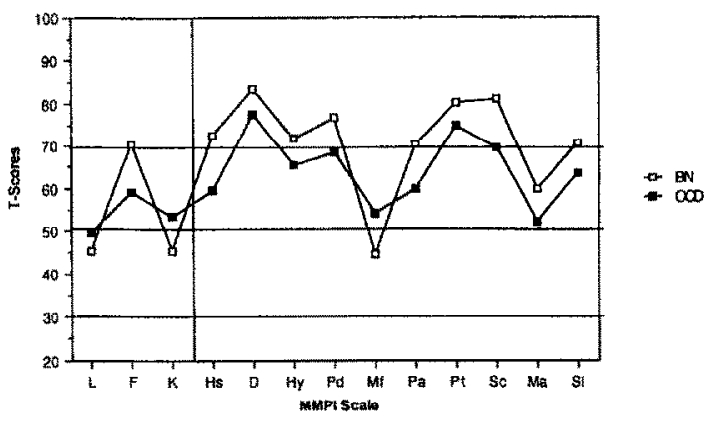

Fig 1. Mean MMPI profiles of BN and OCD women.
Table 1. Chi-Square of Elevations on MMPI Clinical Scales

\begin{tabular}{lcccc}
\hline \multicolumn{1}{c}{ MMPI Scale } & $\begin{array}{c}\text { No. of } \\
\text { BN }(\%)\end{array}$ & $\begin{array}{c}\text { No. of } \\
\text { OCD }(\%)\end{array}$ & $x^{2}$ & $P$ \\
\hline Hypochondriasis & $10(50)$ & $2(10)$ & 5.8 & .02 \\
Depression & $19(95)$ & $15(75)$ & & $.18^{*}$ \\
Hysteria & $11(65)$ & $5(25)$ & 2.6 & .11 \\
Psychopathic deviate & $15(75)$ & $7(35)$ & 4.9 & .03 \\
Masculinity-femininityt & $1(5)$ & $1(5)$ & & $1.0^{*}$ \\
Paranoia & $11(55)$ & $5(25)$ & 2.6 & .11 \\
Psychasthenia & $17(85)$ & $16(80)$ & & $1.0^{*}$ \\
Schizophrenia & $17(85)$ & $11(55)$ & 3.0 & .08 \\
Hypomania & $1(5)$ & $1(5)$ & & $1.0^{*}$ \\
Social introversion & $11(55)$ & $7(35)$ & 0.9 & .34 \\
\hline
\end{tabular}

*Denotes Fisher's exact test probability.

$\dagger T$ scores $<30$

(Wilk's $\Lambda=0.40, \mathrm{~F}=4.1, d f=[10,28]$, $P=.001$ ). Table 2 presents results of the univariate ANCOVAs and posthoc analyses for the scale scores. The fact that more BN than OCD women were hospitalized was reflected in their higher Global Symptom Index (GSI) scores.

\section{Comparison of Underweight Versus \\ Normal-Weight Eating Disorder Samples}

We then attempted to determine whether the high obsessionality evidenced in the BN group was due primarily to those individuals who either were at the time of the study or had a history of low body weight ( $<85 \%$ IBW). To do so, we subdivided the $\mathrm{BN}$ sample into lowweight $(n=9)$ and normal-weight $(n=11)$ groups and performed $t$ tests on the $10 \mathrm{MMPI}$ and 10 SCL-90-R scale scores. The low-weight and normal-weight groups did not differ significantly on any of the MMPI clinical scales. Likewise, there were no significant differences between the two groups on the obsessivecompulsive, anxiety, or phobic anxiety scales of the SCL-90-R. The low-weight bulimics did score significantly higher on interpersonal sensitivity $(81.7 \pm 7.4 \vee 74.3 \pm 7.3, \mathfrak{t}[18]=-2.2$, $P=0.03)$, depression $(76.2 \pm 5.8 \vee 68.5 \pm 7.8$, $\mathrm{t}[18]=-2.4, P=.03)$, hostility $(66.3 \pm 8.4 v$ $57.5 \pm 5.6, \mathrm{t}[18]=-2.5, P=.02)$, psychoticism $(81 \pm 10.6$ v $71.5 \pm 9.5, \mathrm{t}[18]=-2.1, P=.05)$, and the GSI $(77.8 \pm 8.8 v 69.3 \pm 7.8$, $\mathrm{t}[18]=-2.3, P=.003)$

\section{DISCUSSION}

The results of this study show marked similarities between women with $\mathrm{BN}$ and $\mathrm{OCD}$ on trait 
Table 2. Mancova for SCL-90-R Scales and Univariate ANCOVAs

\begin{tabular}{|c|c|c|c|c|c|c|}
\hline \multirow[b]{2}{*}{ SCL-90-R Scale } & \multicolumn{2}{|c|}{$\mathrm{BN}$} & \multicolumn{2}{|c|}{$\mathrm{OCO}$} & \multirow[b]{2}{*}{$\begin{array}{c}F \\
\{d \neq\{2,37]\}\end{array}$} & \multirow[b]{2}{*}{$p$} \\
\hline & $\begin{array}{c}\text { Observed } \\
\text { Mean } \pm S D \\
{[n=20)}\end{array}$ & $\begin{array}{l}\text { Corrected } \\
\text { Mean } \pm S E\end{array}$ & $\begin{array}{c}\text { Observed } \\
\text { Mean } \pm S D \\
(n=20)\end{array}$ & $\begin{array}{c}\text { Corrected } \\
\text { Mcan } \pm \text { SE }\end{array}$ & & \\
\hline Somatization & $66.1 \pm 9.7$ & $65.8 \pm 2.0$ & $52.7 \pm 6.4$ & $53.0 \pm 2.0$ & 12.9 & .0001 \\
\hline Obsessive-compulsive & $73.8 \pm 8.8$ & $72.5 \pm 2.7$ & $68.5 \pm 13.6$ & $69.7 \pm 2.7$ & 1.8 & .18 \\
\hline interpersonal sensitivity & $77.6 \pm 8.1$ & $78.9 \pm 2.4$ & $65.0 \pm 11.8$ & $63.7 \pm 2.4$ & 9.0 & .001 \\
\hline Depression & $72.0 \pm 7.9$ & $72.5 \pm 2.5$ & $64.0 \pm 12.1$ & $63.5 \pm 2.5$ & 3.2 & .05 \\
\hline Anxiety & $66.2 \pm 9.8$ & $66.1 \pm 2.6$ & $65.3+11.3$ & $65.3 \pm 2.6$ & 0.04 & .96 \\
\hline Hostility & $61.5 \pm 8.8$ & $62.1 \pm 1.9$ & $56.3 \pm 6.4$ & $55.6 \pm 1.9$ & 2.7 & .08 \\
\hline Phobic anxiety & $62.9 \pm 9.2$ & $63.1 \pm 2.2$ & $59.3 \pm 9.1$ & $59.0 \pm 2.2$ & 0.8 & .46 \\
\hline Paranoia & $68.6 \pm 10.4$ & $68.9 \pm 2.6$ & $60.5 \pm 11.2$ & $60.1 \pm 2.6$ & 2.8 & .07 \\
\hline Psychoticism & $75.8 \pm 10.8$ & $75.8 \pm 2.9$ & $65.7 \pm 13.2$ & $65.7 \pm 2.9$ & 3.4 & .04 \\
\hline GSI & $73.1 \pm 9.1$ & $73.3 \pm 2.4$ & $63.8 \pm 11.9$ & $63.6 \pm 2.4$ & 4.2 & .02 \\
\hline
\end{tabular}

NOTE. MANCOVA (Wilk's $h=0.40, \mathrm{~F}=4.1$, df $\{10,28\}, P=.001\}$

measures of personality and psychopathology. However, differences did emerge when comparing current symptom profiles of both groups.

On the MMPI, the vast majority of both $\mathrm{BN}$ and OCD women exhibited clinically significant elevations on scales 2 (depression) and 7 (psychasthenia). Elevations on scale 2 suggest depression, social withdrawal, low self-confidence, and physical symptoms commonly associated with depression. Scale 7 elevations in this range are suggestive of anxiety and tension, as well as a fearful and apprehensive state. Obsessions, compulsions, and ruminations are common in individuals with high scores on this scale. They also tend to be perfectionistic, self-critical, and plagued by doubt.

The 2-7-8 profile was common in both groups. Traditionally, this profile reflects depression, anxiety, and nervousness, and strong obsessional characteristics. In addition, the 2-7-8 tends to set high standards and feel guilty when they are not met. Feelings of inadequacy and inferiority are common as is a schizoid personality style.

Differences in MMPI profiles included the more frequent elevation on scale 1 (hypochondriasis) in the bulimic women. This elevation could be due to several factors. One possibility is that the bulimic women did indeed suffer from a variety of physical disturbances secondary to binge-eating, vomiting, poor nutrition, laxative abuse, and electrolyte disturbances, which emerges as a preoccupation with physical complaints or symptoms. Alternatively, the close scrutiny with which bulimics monitor their body size and shape may extend to a vigilance over other somatic symptoms. We will discuss this hypothesis in greater detail below.

A second difference noted in MMPI profiles was that significantly more bulimic than OCD patients showed elevations on scale 4 (psychopathic deviate), which may reflect impaired impulse control commonly thought to be part of the bulimic disturbance ${ }^{29.31}$; however, higher scores on Pd would also be expected in a younger sample. ${ }^{32}$

The greater (although nonsignificant) elevation in the BN group on the MMPI profilc and the significantly higher scores on the BDI and SCL-90-R GSI may well be an artifact of sampling. As $100 \%$ of the $\mathrm{BN}$ subjects required inpatient treatment, only the most severe of $\mathrm{BN}$ patients are represented here. In contrast, only $30 \%$ of OCD women were hospitalized and hence the sample includes a wider range of psychopathology.

The greatest difference between the two groups emerged in the SCL-90-R subscales. Confirming the MMPI results, $\mathrm{BN}$ women scored significantly higher than the OCD women on the somatization scale, which measures distress arising from perceptions of bodily dysfunction by assessing an array of physical complaints. Although the $\mathrm{BN}$ group scored significantly higher than the OCD women, their mean score was not elevated above the clinically significant range $(t>70)$. Again, the higher scores in the BN women could reflect actual disease processes or physical problems secondary to the eating disorder. It is also possible that they, in 
contrast to the OCD patients, focus a great amount of attention to the physical workings of their body and may be hypervigilant to minor physical changes or symptoms. On the other hand, a greater number of OCD patients may have a more externalized focus and spend a greater amount of time scanning the environment for threatening stimuli.

Bulimic women also scored higher on the depression, interpersonal sensitivity, and psychoticism scales. While the D scores confirm the BDI findings, high scores on interpersonal sensitivity suggest feelings of personal inadequacy, inferiority, and extreme social discomfort. This scale includes items that could reflect the bulimic's discomfort about eating and physical appearance such as "feeling uncomfortable about eating or drinking in public" or "feeling uneasy where people are watching or talking about you"; however, it may also reflect a more generalized fear of negative evaluation and discomfort in social situations. Indeed, we have recently shown that both bulimic and anorexic women score comparably high to women with social phobia on the Social Phobia and Anxiety Inventory ${ }^{33}$ and that these elevations are not due solcly to fears of cating in public, but rather reflect a more prototypic social phobic stance. ${ }^{34}$

Finally, the clinically elevated psychoticism scale may less reflect frank psychotic experiences and more tap the socially withdrawn and schizoid life-style that often develops during extreme phases of the bulimic disorder.

It is of particular interest that the $\mathrm{BN}$ women scored comparably to the OCD women on the three SCL-90-R anxiety scales (obsessive-compulsive, phobic anxiety, and anxiety). Although one would expect to find a high degree of anxiety and depression in both of the disorders, the fact that the BN group displayed comparable and numerically higher levels than the OCD patients may be important in the further conceptualization of the disorder. Also, it is of particular interest that the high obsessionality and anxiety scores were not limited to those individuals with current or past-low body weight and that these symptoms also occur in the normalweight bulimia population.

One possible interpretation of these findings is that elevated scores on the OCD scale are due to inclusion by bulimic women of obsessional thoughts and beliefs about body shape, weight, and food. Although worthy of further inquiry, a recent study by Kaye et al. $^{35}$ on anorectic women indicated that they scored comparably to OCD patients reported in the literature on the Yale-Brown Obsessive-Compulsive Scale ${ }^{36,37}$ after exclusion of all body- and food-related items suggesting that obsessionality is not just limited to symptoms of the eating disorder.

It is clear that a fear of weight gain is central to $\mathrm{BN}$; however, our findings indicate that their fears may be as pervasive and complex as those seen in OCD patients. For example, the stimuli that produce anxiety for the bulimic are most likely more than just weight gain. Other specific anxiety-producing stimuli may include stomach fullness, fit of clothes, decreased activity, seeing other thin or obese individuals, sight, taste, and smell of high-risk foods, mirrors, etc. As in $\mathrm{OCD}$, random exposure to these stimuli occurs throughout the day, which leads to heightened vigilance, anxiety, and dysphoria common to both disorders.

Given the similaritics in symptom profiles between $\mathrm{BN}$ and OCD women and the seemingly viable conceptualization of $\mathrm{BN}$ as similar to OCD with patients displaying pervasive obsessional thinking about food and body weight, food-related rituals, and possibly compulsive binging and purging, it is relevant to examine the feasibility of applying treatments known to be effective in OCD to intervention in bulimic women.

The efficacy of fluoxetine for $\mathrm{BN}$, which has been shown to be effective for OCD, ${ }^{38,39}$ has shown initial positive results. ${ }^{40,41}$ In terms of behavioral interventions, exposure with response prevention is considered the treatment of choice for patients with $\mathrm{OCD},,^{39,42}$ with approximately $70 \%$ to $90 \%$ of patients showing moderate to significant symptomatic improvement and gains being maintained in follow-up periods ranging from several months to several years. A debate continues in the literature on $\mathrm{BN}$ as to whether the addition of exposure with response prevention techniques to baseline cognitivebehavioral treatment enhances ${ }^{43,44}$ or detracts from treatment outcome. ${ }^{45}$ Williamson et al. ${ }^{46}$ concluded that ERP (exposure with response 
prevention) is an effective treatment for some bulimics, but that a significant number of patients are not symptom-free at the end of treatment and that relapse prior to follow-up often occurs. Each of the aforementioned studies used exposure to eating with prevention of vomiting. One could question whether the trials were adequate, as all cues were not incorporated, and whether response prevention was correctly applied. Perhaps prevention of bing- ing following exposure to high-risk cues would produce more lasting results.

In summary, this study found marked similarities in trait-related personality and psychopathological features between women with BN and those with OCD. Given the relatively small sample size used here, future studies examining larger numbers of women should continue to explore the nature of anxiety in women with $\mathrm{BN}$ and related eating disturbances.

\section{REFERENCES}

1. Agras W, Kirkley B. Bulimia: theories of etiology. In: Brownell K, Foryet J (eds): Handbook of Eating Disorders: Physiology, Psychology and Treatment of Obesity, Anorexia and Bulimia. New York, NY: Basic Books, 1986:367-378.

2. Kaye WH, Ebert MH, Gwirtsman HE, Weiss SR. Differences in brain serotonergic metabolism between nonbulimic and bulimic patients with anorexia nervosa. Am J Psychiatry 1984;141:1598-1601.

3. Kaye WH, Gwirtsman HE, Brewerton TD, George DT, Jimerson DC, Wurtman RJ. Bingeing behavior and plasma amino acids: a possible involvement of brain serotonin in bulimia. Psychiatry Res 1988;23:31-43

4. Rothenberg A. Eating disorder as a modern obsessivecompulsive syndrome. Psychiatry 1986;49:45-53.

5. Rosen J, Leitenberg H. Bulimia nervosa: treatment with exposure and response prevention. Behav Ther 1982;13: 117-124.

6. Solyom L, Freeman R, Thomas C, Miles J. The comparative psychopathology of anorexia nervosa. Int $\mathrm{J}$ Eating Disord 1983;3:3-13.

7. Pyle RL, Mitchell JE, Eckert ED. Bulimia: a report of 32 cases. J Clin Psychiatry 1981;42:60-64.

8. Hudson J, Pope HG, Jonas JM, Yurgelun-Todd D. Phenomenological relationship of eating disorders to major affective disorders. Psychiatry Res 1983;9:345-354.

9. Mitchell JE, Hatsukami D, Pyle RI, Eckert ED. The bulimia syndrome: course of illness and associated problems. Compr Psychiatry 1986;27:165-170.

10. Rothenberg A. Differential diagnosis of anorexia nervosa and depressive illness: a review of 11 studies. Compr Psychiatry 1988;29:427-432.

11. Hudson JI, Pope HG, Yurgelun-Todd D, Jonas JM, Frankenburg FR. A controlled study of lifetime prevalence of affective and other psychiatric disorders in bulimic outpatients. Am J Psychiatry 1987; 144:1283-1287.

12. Laessle RG, Kittl S, Fichter MM, Wittchen HU, Pirke KM. Major affective disorder in anorexia nervosa and bulimia. Br J Psychiatry 1987;151:785-789.

13. Stern SL, Dixon KN, Nemzer E. Affective disorder in the families of women with normal weight bulimia. $\Lambda \mathrm{m} \mathrm{J}$ Psychiatry 1984;141:1224-1227.

14. Bulik CM. Drug and alcohol use in bulimic women and their families. Am J Psychiatry 1987;144:1604-1606.

15. Kassett JA, Gershon ES, Maxwell ME, Guroff JJ, Kazuba DM, Smith AL, et al. Psychiatric disorders in the first-degree relatives of probands with bulimia nervosa. Am J Psychiatry 1989;146:1468-1471.

16. Hatsukami D, Owen P, Pyle R, Mitchell JE. Similarities and differences on the MMPI between women with bulimia and women with alcohol or drug abuse problems. Addict Behav 1982;7:435-439.

17. Prather R, Williamson D. Psychopathology associated with bulimia, binge eating and obesity. Int J Eating Disord 1988:7:177-184.

18. Williamson DA, Kelley MI, Davis CJ, Ruggiero L, Blouin DC. Psychopathology of eating disorders: a controlled comparison of bulimic, obese and normal subjects. $\mathrm{J}$ Consult Clin Psychol 1985:53:161-166.

19. Carey R, Baer L, Jenike M, Minichiello W, Schwartz C, Regan N. MMPI correlates of obsessive-compulsive disorder. J Clin Psychiatry 1986;47:371-372.

20. Doppelt H. A typological investigation of the MMPI scores of clients with an obsessive-compulsive disorder and the relationship of their MMPI scores to behavioral treatment outcome. Ann Arbor, MI: Disscrtation Abstracts International, 1983.

21. Mezzich J, Dow J, Rich C, Costello A, Himmelhoch $J$. Developing an effective information system for a comprehensive psychiatric institute II: Initial Evaluation Form. Behav Res Methods Instrument 1981;13:464-478.

22. American Psychiatric Association. Diagnostic and Statistical Manual of Mental Disorders. 3rd ed. rev. Washington, DC: American Psychiatric Association Press, 1987.

23. Johnson $C$. The initial consultation for patients with bulimia and anorexia nervosa. In: Garncr DM, Garfinkel E (eds): Handbook of Psychotherapy for Anorexia Nervosa and Bulimia. New York, NY: Guilford, 1985:19-51.

24. DiNardo P, Barlow D, Cerny J, Vermilyea B, Vermilyea I, Himaldi W. Anxiety Disorders Interview ScheduleRevised. Albany, NY: Phobia and Anxiety Disorders Clinic. 1986.

25. Hathaway S, McKinley J. MMPI Manual: Revised Edition. New York, NY: The Psychological Corporation, 1951.

26. Derogatis L. SCL-90-R Administration, Scoring, and Procedures Manual. Baltimore, MD: Clinical Psychometric Research, 1983.

27. Beck A, Ward C, Mendelsohn M. Mock J. Erbaugh J. An inventory for measuring depression. Arch Gen Psychiatry 1961;4:561-571. 
28. SAS Institute. SAS User's Guide: Statistics, Version 6. Cary, NC: SAS Institute, 1990.

29. Russell G. Bulimia nervosa: an ominous variant of anorexia nervosa. Psychol Med 1979;9:429-448.

30. Crisp AH, Hsu LKG, Harding $B$. The starving hoarder and voracious spender: stealing in anorexia nervosa. $J$ Psychosom Med 1980;24:225-231.

31. Garfinkel PE, Garner DM. Subtypes of anorexia nervosa. In: Garfinkel PE, Garner DM (eds): Anorexia Nervosa: A Multidimensional Perspective. New York, NY: Bruner-Mazel, 1982:40-57.

32. Lachar D. The MMPI; Clinical Assessment and Automated Interpretation. WPS Professional Handbook Series, 1973.

33. Turner SM, Beidel DC, Dancu CV, Stanley MA. An empirically derived inventory to measure social fears and anxiety: The Social Phobia and Anxiety Inventory. Psychol Assess 1989;1:35-40.

34. Bulik CM, Beidel DC, Duchmann E, Weltzin TE, Kaye WH. An analysis of social anxiety in anorexic, bulimic, social phobic, and control women. J Psychopath Behav Assess. In Press.

35. Kaye W, Weltzin TE, Hsu LKG, Bulik CM, McConaha $C$, Sobkiewicz T. Patients with anorexia nervosa have elevated scores on the Yale-Brown Obsessive-Compulsive Scale. Int J Eating Disord. In Press.

36. Goodman WK, Price LH, Rasmussen SA, Mazure C, Fleischmann RL, Hill CL, et al. The Yale-Brown ObsessiveCompulsive Scale (Y-BOCS): I. Development, use, and reliability. Arch Gen Psychiatry 1989a;46:1006-1011.

37. Goodman WK, Price LH, Rasmussen SA, Mazure C,
Delgado P, Heninger GR, et al. The Yale-Brown ObsessiveCompulsive Scale (Y-BOCS): II. Validity. Arch Gen Psychiatry 1989b;46:1012-1016.

38. Fontaine R, Chouinard G. An open trial of fluoxetine in the treatment of obsessive-compulsive disorder. $\mathrm{J}$ Clin Psychopharmacol 1986;6:98-101.

39. Turner S, Beidel DC. Treating Obsessive-Compulsive Disorder. New York, NY: Pergamon, 1988.

40. Freeman CL, Hampson M. Fluoxetine as a treatment for bulimia nervosa. Int J Obesity 1987;11:171-177.

41. Jimerson DC, Lesem MD, Hegg AP, Brewerton T. Serotonin in human eating disorders. Ann NY Acad Sci $1990 ; 600: 532-544$.

42. Steketee $\mathrm{G}$, Cleere L. Obsessional-compulsive disorders. In: Bellack AS, Hersen M, Kazdin AF (eds): International Handbook of Behavior Modification and Therapy. New York, NY: Plenum, 1989:307-332.

43. Leitenberg H, Rosen JC, Gross J, Nudelman S, Vara LS. Exposure with response-prevention treatment of bulimia nervosa. J Consult Clin Psychol 1988;56:535-541.

44. Wilson GT, Rossiter E, Kleifeld EI, Lindholm L. Cognitive-behavioral treatment of bulimia nervosa: a controlled evaluation. Behav Res Ther 1986;24:277-288.

45. Agras WS, Schneider JA, Arnow B, Raeburn SD, Telch CF. Cognitive-behavioral and response-prevention treatments for bulimia nervosa. J Consult Clin Psychol 1989;57:215-221.

46. Williamson DA, Davis CJ, Duchmann EG. Anorexia and bulimia nervosa. In: Hasselt VBV, Kolko DJ (eds): Inpatient Behavior Therapy for Children and Adolescents. New York, NY: Plenum, 1990. 